\title{
Antecedentes e consequentes do processo de obtenção e renovação do Certificado de Entidades Beneficentes de Assistência Social (Cebas)
}

Ian Blois Pinheiro

https://orcid.org/0000-0001-9047-782X

Marcia Juliana d'Angelo

https://orcid.org/0000-0003-1436-5812

\section{Resumo}

Objetivo: Identificar os antecedentes e consequentes do processo de obtenção e renovação do Certificado de Entidades Beneficentes de Assistência Social (Cebas) a partir da teoria de Legitimação Organizacional. Método: Pesquisa qualitativa-quantitativa com dados primários (questionário e entrevistas semiestruturadas com os profissionais envolvidos na certificação) e secundários (documentos disponibilizados nos sites dos ministérios) analisados por meio da Templates Analysis e da estatística descritiva.

Resultados: As evidências indicam cinco antecedentes (evidenciação contábil, capacitação e profissionalização das Organizações do Terceiro Setor (OTS) e dos contadores, auditoria externa, insegurança jurídica e outras situações) e quatro consequentes (imunidade tributária, credibilidade das OTS, captação de recursos e mudança cultural) da certificação Cebas. Também indicam as vulnerabilidades controláveis e não controláveis nos antecedentes a serem enfrentadas pelos atores sociais envolvidos com esse processo, que podem comprometer a legitimidade pragmática e moral dessa certificação. A imunidade tributária ainda é um dos principais consequentes desse processo. Algumas OTS não valorizam essa certificação para outros benefícios, como o aumento da credibilidade e, por conseguinte, aumento da captação de recursos, deixando de contribuir para o fortalecimento da legitimidade moral dessa certificação. Contribuições: Para a contabilidade voltada à sustentabilidade, no que diz respeito à formulação de políticas públicas para apoiar o fortalecimento da gestão das OTS. O estudo alerta para a perda de oportunidades de aumentar a quantidade de doadores, nos níveis individual e organizacional, expondo a miopia dessa certificação e para ampliar a literatura sobre certificações ao propor um modelo conceitual para ser testado em futuras pesquisas quantitativas.

Palavras-chave: Certificação Cebas; Terceiro Setor; ITG 2002. Credibilidade. Captação de recursos. 


\section{Introdução}

O terceiro setor é caracterizado no sentido mais amplo pelo seu desejo de promover a mudança social e de agir onde o setor público e privado não conseguem alcançar (Barragato, 2019; Gidron, 2010; Khieng, 2014). No Brasil, há 820 mil organizações da sociedade civil (Ipea, 2018): religiosas (25\%), de esportes (7\%), de educação (5\%), de cultura (3\%), de assistência social (3\%), de saúde (1\%), associações patronais e outras (56\%).

Nesse cenário, 11.868 OTS - 1,4\% do total, que atuam nas áreas da saúde, educação e assistência social possuem o Cebas, de acordo com o Fonif (2018). Trata-se de um certificado emitido pela União, concedido às pessoas jurídicas de direito privado, sem fins lucrativos, legitimadas como entidade beneficente de assistência social' (Brasil, 1988). Dessa forma, essas instituições têm assegurado o direito às imunidades tributárias e prioridade na celebração de convênios com órgãos públicos, em todas as esferas, e com menos burocracia.

Essa certificação, aparentemente, ainda gira em torno de um fator determinante e um fator consequente para a sua obtenção - o atendimento aos requisitos da Interpretação Técnica Geral (ITG) 2002 (CFC, 2012) e a contrapartida das imunidades tributárias, respectivamente (Beuren \& Tamanini, 2009; Lima \& Pereira, 2004). Contudo, trata-se de um segmento que envolve diversos stakeholders (Costa \& Pesci, 2016; Grizzle \& Sloan, 2016; Williams \& Taylor, 2013), muita competição por recursos (Gordon, Knock, \& Neely, 2009; Krasteva \& Yildirim, 2016), pressões por desempenho, maior responsabilização pelos resultados (accountability) (Boateng, Akamavi, \& Ndoro, 2016; Grieco, Michelini, \& Iasevoli, 2015), além da assimetria da informação entre as OTS e os doadores de recursos (Gordon et al., 2009; Ortmann \& Svítková, 2007; Weisbrod \& Dominguez, 1986).

Por isso, é relevante discutir, de forma mais holística, as relações envolvendo a certificação Cebas e, em particular, ampliar o debate dos seus determinantes e efeitos. Diante do exposto, o objetivo desta pesquisa é identificar os antecedentes e consequentes da obtenção e renovação do Certificado das Entidades Beneficentes de Assistência Social a partir da percepção dos profissionais envolvidos com esta certificação. Para tanto, esta discussão se ancorou na teoria de Legitimidade Organizacional (DiMaggio \& Powell, 1983; Suchman, 1995). Trata-se de uma lente teórica que explica por que as organizações se assemelham em função da força da lei, da imitação, padrões de profissionalização tomados como certos (DiMaggio \& Powell, 1983). Essa teoria também discute a percepção da adequação das atividades das organizações ao seu contexto cultural com base nas trocas diretas entre a organização e o seu público de interesse, nos julgamentos acerca dos benefícios das atividades organizacionais, na confiança, previsibilidade, estabilidade e coerência da organização (Suchman, 1995).

$\mathrm{Na}$ literatura nacional, os poucos estudos dessa temática são feitos com amostras restritas, circundadas a contextos específicos e com foco na gestão contábil, um dos principais antecedentes dessa certificação (Beuren \& Tamanini, 2009; Fagundes, Silva, \& Silva, 2014; Lima \& Pereira, 2004; Ramos \& Klann, 2019; Santos, Ohayon, \& Pimenta, 2017). Não foram identificados estudos abarcando os consequentes dessa certificação. E, segundo Yörük (2016, p. 196), o 'impacto de análises de especialistas ou classificações de terceiros nos serviços e produtos fornecidos por OTS é relativamente desconhecido. Há poucos estudos na literatura internacional (Adena, Alizade, Bohner, Harke, \& Mesters, 2019; Brown, Meer, \& Williams, 2017; Gordon et al., 2009; Ortmann \& Svítková, 2007; Svítková, 2013; Yörük, 2016) que investigam o efeito das classificações de terceiros nas doações de caridade.

Considerando que a certificação Cebas se trata de política pública de inclusão social de abrangência nacional, nas áreas da educação, saúde e assistência social, esta pesquisa contribui para a literatura da contabilidade para a sustentabilidade referente à formulação de políticas públicas, ao apresentar um modelo conceitual holístico baseado nos eventos antecedentes e nos efeitos desta certificação, a partir da percepção dos atores sociais envolvidos com este processo. Ao discutir essa certificação, de forma mais holística, ainda não considerada na literatura nacional, o estudo abre o debate para a necessidade de mitigar as vulnerabilidades dessa certificação para fortalecer a sua legitimidade pragmática e moral. Também contribui para os atores sociais, os praticantes envolvidos com a certificação Cebas, ao identificar algumas ações de diligências e capacitação, em particular, para os contadores. 


\section{Referencial Teórico}

\subsection{O Papel da Certificação nos Países Europeus, Africanos e nos Estados Unidos}

Certificação é 'um procedimento pelo qual um ator social independente emite uma garantia por escrito de que um produto, processo ou serviço atende a requisitos específicos' (Auld, Gulbrandsen, \& McDermott, 2008, p. 188). Tem sido aplicada para garantir padrões de gestão e de governança nas áreas sociais (Adena et al., 2019; Brown et al., 2017; Gordon et al., 2009; Svítková, 2013; Yörük, 2016) e ambientais (Atasoy, 2020; Cavero-Rubio \& Amorós-Martínez, 2020; Mohan, 2020; Wen \& Lee, 2020).

$\mathrm{Na}$ área ambiental, a certificação tem sido aplicada no manejo florestal responsável, como a certificação do Forest Stewardship Council (FSC) na zona rural da Tanzânia (África). As evidências mostraram que as famílias que vivem nas adjacências das plantações florestais privadas, certificadas pelo FSC, percebem melhorias nos serviços sociais e na infraestrutura fornecidos em comparação com as plantações estatais, não certificadas (Degnet, van der Werf, Ingram, \& Wesseler, 2018).

Também tem sido aplicada na certificação de edifícios verdes, como a do programa do Leadership in Energy and Environmental Design, que classifica a eficiência energética e sustentabilidade dos edifícios. Atasoy (2020) mostrou que preços de energia mais altos incentivam as organizações a reverem suas posições de classificações no setor da construção nos Estados Unidos.

Nos hotéis espanhóis com a certificação ISO 14001 e Eco-Management and Audit Scheme (EMAS), Cavero-Rubio \& Amorós-Martínez (2020) demonstraram que, durante a crise de 2008, os hotéis certificados obtiveram maiores benefícios do que aqueles sem a certificação. Ou seja, enfrentaram melhor a crise e mantiveram o desempenho financeiro, ao contrário dos não certificados, cujo desempenho financeiro piorou durante a crise.

Ssebunya, Morawetz, Schader, Stolze e Schmid (2019) mostraram que, em relação à certificação Fairtrade, de comércio justo, nos grupos de agricultores de café de longa data em Uganda (África), não houve aumento da renda líquida em função da certificação. Contudo, os rendimentos dos agricultores certificados são $20 \%$ maiores em relação aos não certificados. No que diz respeito aos novos produtores de café arábica, os rendimentos cresceram em função da certificação, enquanto nos produtores de longa data não há diferenças entre os que têm ou não o certificado.

$\mathrm{Na}$ área social, países europeus como Suíça, Noruega, Suécia, França, Alemanha e Holanda já possuem tradição com sistemas de certificação no terceiro setor, assim como os Estados Unidos (Gordon et al., 2009; Ortmann \& Svítková, 2007). Dessa forma, nestes países, os sistemas de classificação (ratings) das OTS têm o papel mitigador da assimetria da informação entre os doadores de recursos e as instituições de caridade em relação à aplicação eficiente e eficaz dos recursos, à qualidade dos serviços prestados e ao fornecimento de informações financeiras (Gordon et al., 2009; Ortmann \& Svítková, 2007; Weisbrod \& Dominguez, 1986). Ou seja, as agências de classificação desempenham o papel de 'fiel da balança' entre esses atores sociais, por meio da análise de dados contábeis, como a saúde financeira, transparência e accountability (responsabilização pelos resultados) das organizações de caridade (Gordon et al., 2009).

Alguns estudos têm demonstrado os efeitos das classificações nas doações às OTS. Nos Estados Unidos, o estudo de (Brown et al., 2017), por meio de um experimento com doadores sobre dez OTS, revelou que a classificação feita por terceiros afeta a escolha da instituição a receber as doações, bem como o montante doado, pelo menos um pouco, e que as OTS locais não têm a preferência dos doadores.

Já Yörük (2016) mostrou que as avaliações da agência de classificação Charity Navigator, que sinalizam a qualidade das instituições beneficentes, têm um impacto menor nas doações. Contudo, as doações são maiores (cerca de 20\%) para as instituições de caridade relativamente menores e desconhecidas, caso tenham altas classificações. A pesquisa foi feita com uma amostra de 5.400 organizações no período de 2007 a 2010. Ao contrário do estudo de Gordon et al. (2009) com a mesma agência, com uma amostra de 525 organizações, com dados do período de 2005 a 2006, que mostrou que, quanto melhor a classificação, maiores as contribuições dos doadores. 
O experimento de Adena et al. (2019), conduzido em Berlim com estudantes universitários, apontou algumas evidências que também merecem reflexões. Primeiro, a certificação de OTS também influencia positivamente o nível de doação. Segundo, o montante doado pelos atuais doadores não aumenta em função do recebimento da informação de que a OTS tem uma certificação em comparação aos possíveis doadores. Terceiro, os custos com a certificação não influenciam as doações. Quarto, a certificação aumenta a confiança nas OTS, que, por sua vez, influencia as doações. Ou seja, para esses autores, a certificação fornecida por agências independentes pode contribuir positivamente para garantir padrões de gestão e de governança dessas OTS.

Para Ortmann \& Svítková (2007) e Svítková (2013), trata-se de uma proposta plausível para países em transição, como os do Leste Europeu, que estão saindo de uma economia planejada para uma economia de mercado, cujas OTS enfrentam desconfiança dos doadores e, por conseguinte, recebem poucas doações. Por meio de um ensaio teórico, mostra os benefícios de uma agência certificadora, como a minimização dos impactos negativos da assimetria de informação, auxiliando os doadores na distinção entre as OTS bem e mal geridas. Outra contribuição seria a abertura de mais OTS com gestão profissionalizada e fortalecida, influenciando na redução das OTS com problemas de gestão e governança.

\subsection{O Papel da Certificação no Brasil na Área Social}

A certificação Cebas é uma ação que se constitui em uma política pública de abrangência nacional de acesso à assistência social, saúde e educação básica e superior, contribuindo para a inclusão social no Brasil. Segundo o Conselho de Monitoramento e Avaliação de Políticas Públicas da Controladoria-Geral da União (2019, p. 10):

A Certificação das Entidades Beneficentes de Assistência Social (CEBAS) trata-se de política pública de abrangência nacional, na qual se concede certificação a pessoas jurídicas de direito privado sem fins lucrativos reconhecidas como entidades beneficentes de assistência social, desde que atendam aos requisitos da lei, com a finalidade de prestação de serviços assistenciais, em contrapartida ao reconhecimento à imunidade de contribuições para a seguridade social, instituída pelo $₫ 7^{\circ}$ do art. 195 da Constituição Federal.

Ou seja, as OTS têm tido um papel relevante na promoção da inclusão social, pois fazem parte de ecossistema de voluntariado, filantropia e associação (Gidron, 2010), preocupadas em oferecer valor social para a sociedade. A inclusão social faz parte dos objetivos de desenvolvimento sustentável da Agenda 2030 das Organizações das Nações Unidas (ONU), principalmente no tocante à educação de qualidade, saúde e bem-estar, redução das desigualdades, trabalho decente e crescimento econômico (ONU, 2015), atendendo à dimensão social da sustentabilidade.

Ao prestar serviços nas áreas de educação, saúde e assistência social, as OTS recebem incentivos públicos como imunidades e isenções fiscais. Porém, há uma diferença entre a imunidade e a isenção tributária. A imunidade está prevista na Constituição brasileira (Brasil, 1988), enquanto a isenção é concedida por meio de lei infraconstitucional. O crédito tributário existe, mas é excluído por um benefício legal. Dessa forma, na imunidade, não há fato gerador do tributo (Bomtempo \& Valadão, 2017).

Conforme a Constituição brasileira, 'as entidades beneficentes de assistência social que obedecem às exigências estabelecidas em lei são isentas das contribuições para a seguridade social' (Brasil, 1988). Já a jurisprudência do Supremo Tribunal Federal (STF) não considera a isenção tal como descrita no texto constitucional (STF, 1996). No entanto, foi levado ao STF a Ação Direta de Constitucionalidade n. ${ }^{\circ} 2.028$ (Brasil, 2000), questionando qual lei deveria ser observada para a garantia de tais direitos. Diante desse impasse, nesta pesquisa, são adotados os mesmos critérios dos ministérios certificadores. 
Impasse à parte, obter e manter a certificação Cebas significa que as OTS podem continuar a usufruir das imunidades sobre o pagamento das contribuições destinadas à seguridade social, a saber: a cota patronal do INSS, Contribuição para Financiamento da Seguridade Social (Cofins), Contribuição Social sobre o Lucro Líquido (CSLL) e o Programa de Integração Social (PIS) sobre a folha de pagamento, além de poderem receber subvenções públicas e transferências governamentais (Brasil, 1988). Em 2017, as instituições filantrópicas obtiveram quase $\mathrm{R} \$ 12$ bilhões de imunidade previdenciária, gerando $\mathrm{R} \$ 88$ bilhões de contrapartida, $\mathrm{R} \$ 7,39$ de retorno para cada $\mathrm{R} \$ 1,00$ de imunidade recebido. O montante do benefício fiscal corresponde a $20 \%$ do total de imunidades e isenções previdenciárias (Fonif, 2018) concedidas a todos os setores da atividade econômica brasileira, conforme Tabela 1.

Tabela 1

Imunidades recebidas pelas OTS no Brasil

\begin{tabular}{lcccc}
\hline & Educação & Saúde & Assistência social & Total \\
\hline Imunidade previdenciária & 4,02 & 6,83 & 1,08 & 11,93 \\
\hline Contrapartida total & 18,74 & 56,43 & 12,93 & 88,11 \\
\hline Retorno da contrapartida para cada $\mathrm{R} \$ 1,00$ & 4,66 & 8,26 & 12,02 & 7,39 \\
\hline
\end{tabular}

* R\$ bilhões

Em relação ao processo de certificação Cebas, vários requisitos devem ser atendidos pelas OTS: estar constituída regularmente como pessoa jurídica de direito privado, sem fins lucrativos, e ser reconhecida como entidade beneficente de assistência social com finalidade de prestação de serviços nas áreas da educação, saúde e assistência social; obedecer ao princípio da universalidade; estar em funcionamento há, no mínimo, doze meses; apresentar as demonstrações contábeis e financeiras, conforme a ITG 2002 (CFC, 2012), dentre outros.

No tocante aos trâmites junto aos ministérios, a OTS protocola o pedido de concessão ou renovação no ministério na qual possui atividade preponderante, com toda a documentação necessária para o pedido, de acordo com a Lei n. ${ }^{\circ}$ 12.101/2009 (Brasil, 2009). O Ministério da Cidadania certifica as entidades da área da assistência social, sendo o atendimento gratuito uma das principais exigências. O Ministério da Saúde atua na certificação das entidades que prestam serviços na área da saúde e que tenham um mínimo de 60\% dos seus atendimentos prestados ao Sistema Único de Saúde (SUS). Já o Ministério da Educação (MEC) certifica instituições que concedem uma bolsa de estudo 100\% gratuita para cada cinco alunos pagantes na educação básica e, na educação superior, para os alunos que atendam ao Programa Universidade para Todos (Prouni) (Brasil, 2009).

Após a recepção da documentação nos ministérios, o processo é analisado seguindo a ordem cronológica dos protocolos. $\mathrm{O}$ analista verifica o atendimento aos requisitos legais, como os relatórios de atividades e demonstrações contábeis. Na ausência de algum documento, a OTS poderá ser diligenciada para complementação. Em seguida, é emitido o parecer final. Se deferido, a OTS poderá usufruir da certificação no período de três a cinco anos, dependendo do seu faturamento. Se indeferido, a organização poderá protocolar recurso no prazo de 30 dias. 
Poucos estudos brasileiros abarcam essa temática. Lima \& Pereira (2004), por meio de uma pesquisa qualitativa, analisaram a apuração e evidenciação dos resultados de uma OTS de ensino superior com certificação Cebas e encontraram evidências de inadequação das práticas contábeis recomendadas pelo Conselho Federal de Contabilidade (CFC). Desta forma, propuseram um modelo de apuração e evidenciação dos resultados para apoiar a tomada de decisão, a gestão das instituições de ensino superior com Cebas. Beuren e Tamanini (2009) revelaram, em um estudo qualitativo com 14 instituições da Associação Catarinense das Fundações Educacionais (Acafe), que a maioria das instituições de ensino superior não conseguiu a renovação do Cebas devido à incapacidade de comprovar uma aplicação mínima de $20 \%$ em ações de beneficência. Fagundes, Silva e Silva (2014) abordaram o panorama normativocontextual de diversas certificações e apontaram que as OTS se deparam com diversas variáveis e processos ao longo das certificações, em função das suas complexidades contextuais, dentre elas, as ineficiências, arbitrariedades, insegurança jurídica e corrupção, que provocam o distanciamento entre OTS e União. Trata-se de uma pesquisa qualitativa comparativa entre as Organizações da Sociedade Civil de Interesse Público (OSCIP), Utilidade Pública Federal (UPF), extinta em 2014, e Cebas, com base na análise de legislações. Santos, Ohayon e Pimenta (2017), ao examinaram o nível de evidenciação voluntária, via website, de informações financeiras e não financeiras das OTS cariocas, por meio de uma pesquisa quantitativa, constataram que 61 OTS que possuem o Cebas apresentam baixos níveis de evidenciação, evitando inclusive, a divulgação nos seus websites.

Ou seja, ao contrário dos estudos mostrados em outros países, no Brasil, a certificação das OTS nem é feita por agências independentes nem há uma classificação ordenada, por exemplo, variando de uma estrela a cinco estrelas, como a classificação Charity Navigator, nos Estados Unidos. No Brasil, está a cargo do Governo federal e classifica as OTS que têm direito às imunidades tributárias.

\subsection{A legitimidade organizacional}

A discussão sobre o papel da certificação no Brasil e em outros países revela que as organizações desejam que suas atividades sejam percebidas como desejáveis, adequadas e apropriadas dentro de qualquer contexto cultural' (Suchman, 1995, p. 586). Tal fenômeno diz respeito à busca pela legitimação de suas atuações, pois competem por recursos, clientes, poder político, legitimidade institucional e adequação social e econômica, segundo DiMaggio e Powell (1983), com base no estudo de Aldrich (1979).

Legitimidade organizacional, para Suchman (1995, p. 574), é 'uma percepção ou suposição generalizada (uma reação dos observadores a alguma organização, como a veem) cujas ações são desejáveis, adequadas ou apropriadas em algum sistema socialmente construído. Ou seja, reflete uma congruência entre os comportamentos da entidade legitimada e as normas, valores, crenças e definições presumivelmente compartilhadas entre algum grupo social'.

Para DiMaggio e Powell (1983), na legitimidade organizacional institucional há três mecanismos de mudança isomórfica. As forças coercitivas envolvem pressões e persuasões externas, formais e informais, de outros stakeholders, como a força da lei (Código Florestal, contratação de pessoas com deficiência, ações afirmativas nas universidades públicas). Há, pois, uma relação de dependência entre as organizações e as expectativas culturais da sociedade.

As forças miméticas são uma resposta à incerteza, pressionando as organizações a imitarem práticas adotadas por outras organizações, não necessariamente com eficácia comprovada (Balanced ScoreCard, Sistema Integrado de Gestão). Já as forças normativas são pressões para se alcançar padrões de profissionalização considerados eficazes pela comunidade profissional (certificações, normas contábeis), decorrentes das redes de relacionamento profissional originadas na educação formal (universidades) em consultorias de gestão empresarial e de treinamentos, nas associações e por meio da contratação de profissionais bem-sucedidos em outras organizações (DiMaggio \& Powell, 1983). 
Já Suchman (1995) entende que as organizações buscam a legitimidade visando à continuidade (estabilidade) dos seus negócios e a credibilidade (a percepção de que a organização é coerente, previsível e mais confiável) junto a uma audiência, por exemplo, dos stakeholders. As organizações também visam ao suporte ativo (uma intervenção prolongada da sua audiência) e passivo (condescendência da sua audiência, pois a organização deseja fazer negócios em paz, sem a intervenção da audiência). Assim, propõe três tipos de legitimidade organizacional consoantes com o seu conceito discutido acima - pragmática, moral e cognitiva.

O foco da legitimidade pragmática são os interesses do seu público de interesse mais imediato e as relações de trocas diretas (legitimidade de troca) entre a organização e esse público e as de interdependências políticas, econômicas ou sociais. Isto é, esse público se beneficia das respostas dadas a seus interesses (legitimidade de influência), ao contribuir para a formulação de políticas ou quando a organização adota práticas desse público de interesse. Esse público também pode estar disposto a conceder legitimidade àquelas organizações julgadas por serem aparentemente honestas, confiáveis e éticas (legitimidade de disposição). As estratégias para ganhar essa legitimidade envolvem conformidade com as demandas, resposta às necessidades de diversos atores sociais, construção de uma reputação forte, além de fazer publicidade. Para mantê-la, recomenda-se perceber as mudanças e prever os desafios, zelar pelas operações internas para evitar erros. Já para repará-la, a organização pode negar o problema para ganhar tempo ou criar mecanismos de vigilância, como ouvidoria, serviço de atendimento ao consumidor (Suchman, 1995).

A legitimidade moral decorre da avaliação normativa positiva pelo seu público de interesse. Diz respeito ao julgamento dos benefícios das atividades organizacionais para o bem-estar societal (legitimidade de consequências). Também pode ser decorrente da adoção de técnicas e procedimentos socialmente aceitos (legitimidade processual) ou da avaliação de que a organização tem estruturas socialmente construídas que lhes permite atuar adequadamente (legitimidade estrutural). Finalmente, pode se basear na personalidade carismática dos líderes organizacionais (legitimidade pessoal). As estratégias para ganhar essa legitimidade envolvem resultados concretos e meritórios ao se conformar aos ideais altruístas. Para mantê-la, recomenda-se monitorar a ética e proteger a propriedade. Já para repará-la, a organização pode lançar mão do pedido de desculpas e justificar o seu comportamento ou mesmo agir para se dissociar das más influências, por exemplo, contratando novos gestores (Suchman, 1995).

Já a legitimidade cognitiva decorre da 'aceitação da organização como necessária ou inevitável com base em alguma consideração cultural dada como certa'. Assim, decorre a partir de modelos culturais que abranjam a plausibilidade, previsibilidade, inevitabilidade e permanência da organização, contribuindo para a clareza e compreensão dos seus negócios (Suchman, 1995, p. 582). As estratégias para ganhar essa legitimidade envolvem se conformar com os padrões estabelecidos, imitando-os, profissionalizando as operações e buscando certificações. Outra estratégia é padronizar novos modelos/padrões. Para mantê-la, recomenda-se monitorar as expectativas do público de interesse da organização. Para repará-la, explicarse a esse público (Suchman, 1995).

Certificações como Forest Stewardship Council (FSC) legitimam os negócios no sistema florestal ao atestar cadeias de suprimentos, contribuindo para o fortalecimento da sustentabilidade e biodiversidade (Schepers, 2010). Contudo, tal legitimidade pode estar em risco, segundo o estudo de Niedziałkowski e Shkaruba (2018), na Polônia, em função de desacordos entre atores florestais e organizações não governamentais, demandando por uma intervenção do governo. Schepers (2010) já apontara os desafios para a legitimidade pragmática e moral dessa certificação: a existência de esquemas alternativos, a falta de acesso ao mercado, a plantação, o custo da certificação e a extração ilegal de madeira. 


\section{Metodologia}

Para compreender de forma holística os antecedentes e consequentes da certificação Cebas, foi conduzida uma pesquisa qualitativa-quantitativa. A pesquisa qualitativa interpretativa permitiu compreender a percepção dos profissionais envolvidos com essa certificação para entender esse fenômeno organizacional (Merriam, 1998). A pesquisa quantitativa mostrou o nível de adesão aos requisitos da ITG 2002 (CFC, 2012).

A população abrange as OTS que possuem processo de certificação Cebas nos Ministérios da Educação, Saúde e Cidadania. Foram utilizados dados primários a partir da aplicação de questionário e entrevistas semiestruturadas e dados secundários de arquivos disponibilizados nos sites dos ministérios, como o Sistema de Certificação das Entidades Beneficentes de Assistência Social em Saúde, Educação e Assistência Social, cartilhas com explicações do processo disponíveis nos sites dos ministérios e legislações pertinentes ao tema.

\subsection{Dados Quantitativos}

Como não foi possível obter os dados junto aos ministérios certificadores, com base na Lei de Acesso à Informação, sob a alegação de informações protegidas por sigilo fiscal, foi criada uma base de dados a partir do número do Cadastro Nacional da Pessoa Jurídica (CNPJ) e do endereço eletrônico constante dos registros públicos no site da Receita Federal das organizações certificadas. Dessa forma, foram catalogadas 542 OTS.

Foi desenvolvido um questionário com 39 perguntas elaboradas e adaptadas ao terceiro setor a partir dos estudos de Santos, Ponte e Mapurunga (2014) e Ramos e Klann (2019). As respostas são do tipo binárias (sim/não) e categóricas. Esse questionário foi disponibilizado no aplicativo Google Forms e distribuído por e-mail para as 542 OTS. Foram recebidas 39 respostas válidas, um retorno de $7 \%$.

Desse total, 37\% das OTS obtiveram a certificação Cebas, 16\% tiveram o processo indeferido, 21\% ainda estão em processo de análise e $26 \%$ disseram que, embora a certificação se aplique à instituição, nunca foi solicitado. Quanto à natureza jurídica, $86 \%$ são associações e $14 \%$ são entidades religiosas. Em relação à área de atuação, $64 \%$ estão na educação, $29 \%$ na assistência social e $7 \%$ na saúde. Quanto ao porte das OTS, $71 \%$ têm faturamento anual superior a $\mathrm{R} \$ 4,8$ milhões, ou seja, grandes organizações (Brasil, 2009). Pelo critério de quantidade de empregados, $50 \%$ são de porte grande (mais de 100 empregados), 29\% são médias (até 99 empregados) e 21\% são pequenas organizações (até 19 empregados).

\subsection{Dados Qualitativos}

As entrevistas semiestruturadas foram realizadas com 17 profissionais de OTS e com um promotor de justiça que atua na fiscalização das OTS, abrangendo sete unidades da federação, conforme a Tabela 2. No total, os entrevistados atuam com 1.084 OTS, sendo que mais de $95 \%$ possuem a certificação Cebas. Quanto ao perfil dos entrevistados, $41 \%$ têm formação em contabilidade, 29\%, jurídica, 17\%, em serviço social e $13 \%$ possuem outras formações acadêmicas. Trata-se de 'painel de especialistas' de diversas áreas, com papéis e responsabilidades distintos, trabalhando em organizações de portes diferentes em várias regiões do país, cujo olhar para o fenômeno da certificação Cebas contribuiu para se obter e compreender as experiências e os significados a partir de uma perspectiva multiprofissional e mais holística desse fenômeno. 
Já a análise de dados foi realizada utilizando-se a técnica de Template Analysis (Análise de Temas), de King (2004), que possibilita a criação de hierarquias de temas de forma ilimitada e ajustável. Nesta pesquisa, os temas são os significados e as experiências dos atores sociais envolvidos com o fenômeno da certificação Cebas. Essa técnica é aplicada em pesquisas exploratórias, quando se conhece muito pouco sobre o fenômeno estudado - caso desta pesquisa, ao considerar o ambiente brasileiro -, que objetiva uma discussão mais holística voltada aos antecedentes e consequentes dessa certificação. Esses temas são codificados (rótulos/categorias) que podem emergir dos dados e da literatura.

Tabela 2

Relação dos entrevistados

\begin{tabular}{ccclllc}
\hline$\#$ & Estado & Idade & Sexo & Formação Acadêmica & \multicolumn{1}{c}{ Cargo } & $\begin{array}{c}\text { Qte de OTS } \\
\text { representadas }\end{array}$ \\
\hline$\# 1$ & PA & 47 & Feminino & Contadora & Gerente Contábil & 17 \\
\hline$\# 2$ & CE & 42 & Masculino & Contador & Sócio Auditor & 18 \\
\hline$\# 4$ & DF & 44 & Feminino & Economista & Coord. Administrativa & 1 \\
\hline$\# 5$ & PA & 35 & Feminino & Serviço Social & Assistente Social & 1 \\
\hline$\# 6$ & SP & 48 & Masculino & Advogado e Contador & Presidente & 4 \\
\hline$\# 7$ & PA & 32 & Masculino & Contador & Contador & 400 \\
\hline$\# 8$ & RS & 74 & Masculino & Contador & CEO & 1 \\
\hline$\# 9$ & DF & 43 & Feminino & Advogada & Advogada & 276 \\
\hline$\# 10$ & ES & 35 & Masculino & Assistente Social & Superintendente & 1 \\
\hline$\# 11$ & SP & 49 & Masculino & Contador e Engenheiro civil & Sócio-Diretor & 120 \\
\hline$\# 12$ & DF & 57 & Masculino & Bacharel em Direito & Procurador de Justiça & 0 \\
\hline$\# 13$ & SP & 49 & Masculino & Advogado & Sócio Titular & 7 \\
\hline$\# 14$ & DF & 43 & Masculino & Advogado & Sócio Titular & 50 \\
\hline$\# 15$ & PA & 51 & Feminino & Administradora & Coordenadora financeira & 6 \\
\hline$\# 16$ & PA & 43 & Masculino & Contador & Contador & 15 \\
\hline$\# 17$ & CE & 44 & Feminino & Assistente social & Sócia - Consultora & 8 \\
\hline$\# 18$ & ES & 30 & Feminino & Contador & Gerente & 109 \\
\hline
\end{tabular}


Assim, conforme mostrado na Figura 1, foram criados dois códigos de primeiro nível a partir dos objetivos da pesquisa: antecedentes da obtenção e renovação da certificação Cebas e efeitos da obtenção e renovação da certificação Cebas. Para o código antecedentes da obtenção e renovação da certificação Cebas, emergiram cinco códigos de segundo nível e 12 códigos de terceiro nível, a partir de 46 fragmentos das entrevistas. Para o código efeitos da obtenção e renovação da certificação Cebas, surgiram quatro códigos de segundo nível e oito códigos de terceiro nível, a partir de 23 fragmentos das entrevistas.

\begin{tabular}{|c|c|c|}
\hline $\begin{array}{l}\text { Códigos de } \\
1^{\circ} \text { Nível }\end{array}$ & Códigos de $2^{\circ}$ Nível & Códigos de $3^{\circ}$ Nível \\
\hline \multirow{12}{*}{$\begin{array}{l}\text { 1. Antecedentes } \\
\text { da obtenção } \\
\text { e renovação } \\
\text { da certificação } \\
\text { CEBAS }\end{array}$} & \multirow{3}{*}{ 1.1 Evidenciação contábil } & 1.1.1 Dificuldade no levantamento das informações contábeis \\
\hline & & $\begin{array}{l}\text { 1.1.2 Não atendimento aos requisitos mínimos da ITG } 2002 \text { e de } \\
\text { contabilidade }\end{array}$ \\
\hline & & 1.1.3 Divergência entre os relatórios e as atividades executadas \\
\hline & $\begin{array}{l}1.2 \text { Capacitação e } \\
\text { profissionalização dos envolvidos }\end{array}$ & $\begin{array}{l}\text { 1.2.1 Falta de profissionalização da gestão e de capacitação dos } \\
\text { envolvidos com a certificação CEBAS nas OTS }\end{array}$ \\
\hline & \multirow{3}{*}{$\begin{array}{l}\text { 1.3 Relevância da auditoria } \\
\text { externa (independente) nas OTS }\end{array}$} & 1.3.1 Papel da auditoria externa \\
\hline & & 1.3.2 Benefícios da auditoria externa \\
\hline & & 1.3.3 Critérios para a contratação de serviços de auditoria externa \\
\hline & 1.4 Insegurança jurídica & 1.4.1 Mudanças legais \\
\hline & \multirow{4}{*}{1.5 Outras situações } & 1.5.1 Lentidão do processo \\
\hline & & 1.5.2 Não recebimento do processo pelos ministérios \\
\hline & & 1.5.3 Inutilização das informações e documentos contábeis \\
\hline & & 1.5.4 Tomada de decisão indevida \\
\hline \multirow{8}{*}{$\begin{array}{l}\text { 2. Efeitos da } \\
\text { obtenção e } \\
\text { renovação da } \\
\text { certificação } \\
\text { CEBAS }\end{array}$} & 2.1 Imunidade tributária & 2.1.1 Benefícios tributários \\
\hline & \multirow{4}{*}{ 2.2 Maior credibilidade das OTS } & 2.2.1 Tratamento diferenciado junto ao poder público \\
\hline & & 2.2.2 Formação de parcerias público-privadas \\
\hline & & 2.2.3 Melhoria da Imagem da instituição \\
\hline & & 2.2.4 Segurança aos mantenedores são estrangeiros \\
\hline & \multirow{2}{*}{$\begin{array}{l}2.3 \text { Impactos na captação de } \\
\text { recursos }\end{array}$} & 2.3.1 Benefícios / influência do CEBAS \\
\hline & & 2.3.2 Pouca influência do CEBAS \\
\hline & 2.4 A mudança cultural & 2.4.1 Mudança do papel do contador \\
\hline
\end{tabular}

Figura 1. Resumo da análise de Templates 


\section{Análise de Dados}

\subsection{Antecedentes da Certificação Cebas}

Evidenciação fiscal. No caso das OTS, diz respeito ao cumprimento das normas e exigências contábeis constantes na ITG 2002 (CFC, 2012). Nesta pesquisa, 39 OTS cumprem cerca de $81 \%$ dessas exigências, conforme mostrado na Tabela 3. Já os motivos para o não cumprimento da legislação são seis: dificuldade no levantamento das informações contábeis, registro incorreto das ações/atividades das OTS, divergência entre os relatórios e as atividades executadas, não atendimento aos requisitos mínimos da ITG 2002 (CFC, 2012) e requisitos básicos de contabilidade e não observância das normas do CFC.

A dificuldade no levantamento das informações contábeis envolve as questões contábeis, o cruzamento dos dados das instituições com os dados sociais e falhas nas elaborações das demonstrações contábeis, segundo o entrevistado \#02. Também tem a ver com a formatação do processo por causa de dados contábeis, principalmente no cruzamento de informações da contabilidade com os dados do serviço social. O entrevistado \#05 entende que se trata de processo muito complexo, principalmente em organizações com filiais que precisam enviar os dados para a matriz. Além disso, segundo o entrevistado \#16, falta histórico contábil e os estatutos estão em desacordo com a legislação. Para o entrevistado \#08, 'o mais difícil é a adequação do sistema contábil ao atendimento da legislação específica. Os demonstrativos contábeis têm o foco na legislação social e não fiscal'.

O não atendimento aos requisitos mínimos da ITG 2002 (CFC, 2012) e da contabilidade, que acarreta o registro incorreto das ações/atividades das OTS, como a escrituração contábil. Para os entrevistados \#14 e \#17, existe uma fragilidade considerável na escrituração contábil das instituições. A contabilidade de algumas instituições normalmente é feita por contadores que fazem o registro pelo regime de caixa. Outras não fazem a segregação da contabilidade por atividade. O entrevistado \#14, por exemplo, já participou de eventos nos quais os representantes dos Ministérios da Educação e da Cidadania informaram que aproximadamente $60 \%$ dos indeferimentos dos certificados são motivados por erros de escrituração contábil.

Por um lado, muitas instituições cumprem todos os trâmites da Lei n. ${ }^{0}$ 12.101/2009 (Brasil, 2009). Por outro, não observam as normas do Conselho Federal de Contabilidade, gerando fragilidades na Receita Federal do Brasil e nos ministérios. Ou seja, a entidade presta o serviço, mas por um problema contábil não consegue usufruir do benefício tributário (entrevistado \#06). Segundo o entrevistado \#11, 'um determinado custo do projeto não é identificado de maneira correta, vital para o projeto, e essa informação não é contemplada de maneira correta nas demonstrações'.

Também envolve a apuração dos resultados pelo regime de caixa, ausência de declarações como notas explicativas, falta de segregação das demonstrações contábeis (entrevistado \#17). Há também o uso indevido de terminologias da área comercial, não usadas pelas instituições do terceiro setor, como "lucros" e "prejuízos", nas demonstrações contábeis, mostrando falta de conhecimento da norma específica. 
Tabela 3

\section{Análise descritiva}

\begin{tabular}{|c|c|c|c|}
\hline & $\mathbf{n}=39$ & Média & DP \\
\hline \multirow{5}{*}{$\begin{array}{l}\text { Balanço } \\
\text { patrimonial }\end{array}$} & $\begin{array}{l}\text { 1. A entidade apresenta na estrutura do BP a subdivisão dos grupos de ativo e } \\
\text { passivo em circulante e não circulante? }\end{array}$ & 0,974 & 0,160 \\
\hline & 2. A entidade registra o valor do superávit ou déficit do exercício em conta própria do BP? & 0,974 & 0,160 \\
\hline & 3. A Instituição elabora o Balanço Patrimonial (BP)? & 0,949 & 0,223 \\
\hline & 4. A organização registra os recursos de convênios em contas próprias de ativo e passivo? & 0,949 & 0,223 \\
\hline & 5. No BP, está evidente o grupo do Patrimônio Líquido da organização? & 0,846 & 0,366 \\
\hline & Média & 0,938 & 0,227 \\
\hline \multirow{8}{*}{$\begin{array}{l}\text { Demonstração } \\
\text { do Resultado } \\
\text { do Exercício }\end{array}$} & 6. A organização utiliza o regime de competência para o registro dos fatos contábeis? & 0,974 & 0,160 \\
\hline & 7. A Instituição elabora a DRE? & 0,923 & 0,270 \\
\hline & 8. A demonstração apresenta o resultado (superávit ou déficit) do período? & 0,846 & 0,366 \\
\hline & 9. As receitas estão classificadas por programas/atividades de geração de receita? & 0,846 & 0,366 \\
\hline & 10. Os custos e despesas estão apresentados por programas/atividades? & 0,821 & 0,389 \\
\hline & 11. As receitas são subdividas em receitas com ou sem restrições? & 0,795 & 0,409 \\
\hline & 12. O Registro das doações recebidas é feito em qual grupo de contas? & 0,641 & 0,486 \\
\hline & 13. Os Serviços voluntários são registrados? & 0,513 & 0,506 \\
\hline & Média & 0,795 & 0,369 \\
\hline \multirow{4}{*}{$\begin{array}{l}\text { Demais } \\
\text { demonstrações } \\
\text { contábeis }\end{array}$} & 14. A instituição elabora a Demonstração de Fluxo de Caixa? & 0,923 & 0,270 \\
\hline & 15. A instituição elabora a Demonstrações das Mutações do Patrimônio Líquido (DMPL)? & 0,872 & 0,339 \\
\hline & 16. Qual o método de elaboração da Demonstração de Fluxo de Caixa? & 0,359 & 0,486 \\
\hline & Média & 0,718 & 0,365 \\
\hline \multirow{17}{*}{$\begin{array}{l}\text { Notas } \\
\text { Explicativas }\end{array}$} & 17. A Instituição elabora as Notas Explicativas? & 0,949 & 0,223 \\
\hline & $\begin{array}{l}\text { 18. Apresenta o contexto operacional da entidade, incluindo a natureza social, } \\
\text { econômica e os objetivos sociais? }\end{array}$ & 0,897 & 0,307 \\
\hline & $\begin{array}{l}\text { 19. Apresenta os critérios de apuração da receita e da despesa, especialmente com } \\
\text { gratuidade, doação, subvenção, contribuição e aplicação de recursos? }\end{array}$ & 0,872 & 0,339 \\
\hline & 20. Divulga a norma contábil que é utilizada para determinação das práticas contábeis? & 0,846 & 0,366 \\
\hline & $\begin{array}{l}\text { 21. São divulgados os critérios e procedimentos do registro contábil de } \\
\text { depreciação, amortização e exaustão do ativo imobilizado, devendo ser observada } \\
\text { a obrigatoriedade do reconhecimento com base em estimativa de sua vida útil? }\end{array}$ & 0,846 & 0,366 \\
\hline & $\begin{array}{l}\text { 22. Está presente nas notas explicativas a declaração de conformidade com as normas, } \\
\text { interpretações e comunicados técnicos do Conselho Federal de Contabilidade? }\end{array}$ & 0,821 & 0,389 \\
\hline & $\begin{array}{l}\text { 23. As renúncias fiscais relacionadas com a atividade são evidenciadas nas } \\
\text { demonstrações contábeis como se fosse a obrigação devida? }\end{array}$ & 0,769 & 0,427 \\
\hline & $\begin{array}{l}\text { 24. Nas Notas Explicativas, são divulgadas as informações relacionadas às } \\
\text { gratuidades concedidas e serviços voluntários obtidos por tipo de atividade? }\end{array}$ & 0,769 & 0,427 \\
\hline & 25. Apresenta o resumo das políticas contábeis? & 0,744 & 0,442 \\
\hline & $\begin{array}{l}\text { 26. No resumo das políticas contábeis, a entidade divulga as bases de mensuração } \\
\text { e outras políticas contábeis utilizadas que sejam relevantes? }\end{array}$ & 0,744 & 0,442 \\
\hline & $\begin{array}{l}\text { 27. É apresentada a segregação dos atendimentos com recursos próprios dos } \\
\text { demais atendimentos realizados pela entidade? }\end{array}$ & 0,744 & 0,442 \\
\hline & $\begin{array}{l}\text { 28. Dispõe de informações de suporte de itens das demonstrações pela ordem e } \\
\text { com rubricas que são apresentadas? }\end{array}$ & 0,718 & 0,456 \\
\hline & $\begin{array}{l}\text { 29. Demonstram as subvenções recebidas pela entidade, a aplicação dos recursos e } \\
\text { as responsabilidades decorrentes dessas subvenções? }\end{array}$ & 0,718 & 0,456 \\
\hline & $\begin{array}{l}\text { 30. São apresentadas todas as gratuidades praticadas de forma segregada, destacando } \\
\text { aquelas que devem ser utilizadas na prestação de contas aos órgãos governamentais? }\end{array}$ & 0,692 & 0,468 \\
\hline & $\begin{array}{l}\text { 31. Demonstram as subvenções recebidas pela entidade, a aplicação dos recursos e } \\
\text { as responsabilidades decorrentes dessas subvenções? }\end{array}$ & 0,615 & 0,493 \\
\hline & Média & 0,783 & 0,403 \\
\hline & Média geral & 0,805 & 0,362 \\
\hline
\end{tabular}

Notas: Pergunta 13: Por um valor simbólico ou valor real de mercado (1). Não fazemos registro de serviços voluntários (0); pergunta 12: Receitas operacionais (1); Receitas não operacionais (0); pergunta 16: Direto (1); indireto (0).

Fonte: elaborado pelos autores a partir dos estudos de Santos, Ponte e Mapurunga (2014) e Ramos e Klann (2019). 
A divergência entre os relatórios e as atividades executadas diz respeito à falta de organização das instituições, impactando a coleta das informações necessárias para a elaboração dos relatórios de atividades, segundo o entrevistado \#09. Por exemplo, nas OTS de educação, os problemas envolvem a seleção irregular de alunos bolsistas (entrevistado \#14). Nas OTS de saúde, há irregularidade com o Sistema Único de Saúde (SUS,) não atingindo o percentual necessário (entrevistados \#09 e \#14). Nas OTS de assistência social, o principal problema é a preponderância das atividades. (\#14). As OTS têm dificuldade de relatarem o que fazem, ou seja, de comprovarem as atividades, bem como os resultados, refletindo nas prestações de contas, que não são claras o suficiente para que o órgão controlador possa verificar se a instituição cumpriu seus objetivos, de acordo com o entrevistado \#12. Essas dificuldades geram divergências entre o balanço patrimonial e os dados do serviço social enviados aos ministérios, conforme relatado pelo entrevistado \#04.

Capacitação e profissionalização das OTS e contadores. A falta de profissionalização da gestão e de capacitação dos envolvidos com a certificação Cebas nas OTS é um dos motivos dos indeferimentos das instituições que possuem a certificação, para o entrevistado \#08. Falta gestão contábil nas OTS. Por exemplo, muitas vezes, os hospitais possuem uma equipe médica de excelente qualidade e equipamentos de última geração, mas a equipe contábil não acompanha a realidade da instituição, ou seja, há um distanciamento entre os setores da contabilidade e do serviço social nas OTS, segundo o entrevistado \#02. No mesmo sentido, o entrevistado \#17 relata que a falta de capacitação da equipe técnica nas OTS atrapalha os relatórios contábeis. Por causa de erros de informações, as inconsistências das informações são muito grandes, verificados somente por ocasião do cruzamento de informações.

Foco restrito na gestão social e não na administrativa. Na essência, todas as OTS são de interesse público social, mas como o foco não está na gestão, os processos administrativos passam despercebidos. Por exemplo, muitos perdem os prazos de renovação das diretorias porque não estão atentos às questões formais, e sim à prática social (entrevistado \#11). Falta conhecimento e há pouca capacitação dos contadores, que alegam desconhecimento da legislação do terceiro setor, acarretando a falta de demonstrações contábeis obrigatórias, como as notas explicativas. $\mathrm{O}$ entrevistado \#13 relatou que, às vezes, o contador é muito bom para fazer contabilidade de comércio em geral, mas não conhece a norma ITG 2002 (CFC, 2012). Na maioria das vezes, não se observa as normas do Cebas; somente as normas contábeis gerais. Segundo o entrevistado \#1, em um processo na Previdência Social, a entidade tinha atividades preponderantemente religiosas e não de assistência social. E quem deu assessoria não tinha conhecimento sobre a certificação Ceba, além de a prestação de contas ter sido feita de maneira intempestiva, ou seja, fora do prazo legal.

O entrevistado \#17 resume essa percepção de falta de profissionalização da gestão e de capacitação dos envolvidos com a certificação Cebas nas OTS: 'Existe pouco profissionalismo e muita afeição pela instituição'. Em relação às respostas do questionário, quanto ao responsável pela elaboração das demonstrações contábeis, $79 \%$ contratam serviços de contabilidade, 14\% trabalham com contadores autônomos e 7\% utilizam o contador da própria instituição, sendo que $85 \%$ dos profissionais contratados são especializados no terceiro setor. Ou seja, as OTS estão contratando, sim, profissionais que conhecem pouco o terceiro setor.

Auditoria externa (independente) nas OTS. O papel da auditoria não é nem de uma revisão de demonstrações contábeis nem de uma fiscalização. Trata-se, pois, de uma confirmação de integridade e conformidade (entrevistado \#06), dando transparência ao processo (entrevistado \#18) e proporcionando uma verificação preventiva para as instituições sociais das prestações de contas (entrevistado \#02). As OTS, normalmente, só fazem auditoria independente para atenderem a uma obrigatoriedade legal. Para o entrevistado \#14, existe uma cultura de muita resistência de contratação de auditoria quando não há essa obrigatoriedade.

Segundo o entrevistado \#06, muitas vezes, para diminuir o custo do fluxo de caixa, as OTS têm procurado baratear os serviços de auditoria. Algumas instituições buscam empresas de auditoria que diminuam os testes e o tempo de prestação de serviços, comprometendo, por vezes, a execução desses serviços. As OTS que dividem o ciclo de auditoria em duas etapas têm um nível de conformidade muito melhor e maior. A auditoria externa tem como benefício o acompanhamento preventivo para as OTS, cruzando dados e assegurando o controle e a fidelidade dos demonstrativos. Para os entrevistados \#03 e \#16, a auditoria é o último nível de conferência da OTS, gerando melhorias na prestação de contas e nos processos internos. 
Os critérios para a contratação de serviços de auditoria externa abrangem reputação e expertise no terceiro setor (entrevistado \#15), referências de mercado, motivos orçamentários (entrevistado \#03), pesquisa por meio de outras instituições e a consulta em órgãos reguladores (entrevistado \#07. Para o entrevistado \#12, as entidades pequenas não têm condições de contratar auditorias. Às vezes, não têm recursos nem para pagar o contador. $\mathrm{O}$ entrevistado \#10 relatou que não tem auditoria por motivos orçamentários, mas que está no planejamento da organização. Já para os respondentes do questionário, $33 \%$ também alegam os mesmos motivos para a não contratação. Dentre a parcela que utiliza auditores independentes (67\%), nenhuma recorre a grandes empresas internacionais de auditoria nem a serviços de organizações situadas na mesma cidade da instituição. Dentre as empresas contratadas, somente $58 \%$ atuam exclusivamente no terceiro setor. Além disso, $67 \%$ tendem a contratar a mesma empresa por mais de três anos, mostrando que, aparentemente, estas, de fato, estão agregando valor ao processo de certificação Cebas.

Insegurança jurídica. Há uma ação de inconstitucionalidade contra a n. ${ }^{\circ}$ Lei 12.101/2009 (Brasil, 2009), o que alteraria as obrigações na manutenção do Cebas. Para o entrevistado \#10, 'há uma guerra dos certificados'. Ou seja, não deveria haver essa certificação porque outras legislações, como o Art. 14 do Código Tributário Nacional, já garante os mesmos benefícios. O entrevistado \#14 relatou que, nos últimos 25 anos, houve quatro grandes mudanças legais, com intensas batalhas nos tribunais, inclusive nas cortes superiores, com questões de inconstitucionalidade da legislação.

Atualmente, tramita no Supremo Tribunal Federal a Ação Direta de Inconstitucionalidade (Adin) n. ${ }^{\circ}$ 2.028, protocolada em 13/7/1999, que discute a imunidade tributária das organizações filantrópicas. Essa ação abarca as contradições e dúvidas nos acórdãos, principalmente no que diz respeito ao Recurso Extraordinário 566622, segundo o qual "os requisitos para o gozo de imunidade hão de estar previstos em lei complementar". Ao longo do processo de tramitação da Adin citada, foi editada a Lei n. ${ }^{\circ}$ 12.101/2009 (Brasil, 2009), legislação que revogou os artigos motivadores da inconstitucionalidade e manteve alguns dos condicionantes previstos nas legislações anteriores a respeito das condições para a obtenção da certificação, além de definir outros critérios que regulamentaram dispositivos pertinentes da Constituição Federal (Brasil, 1988).

Outras situações envolvem: lentidão do procedimento de concessão da certificação Cebas, o não recebimento do processo pelos ministérios, a inutilização das informações pelas OTS e o descumprimento das exigências das portarias e dos critérios contábeis. Possuir mais de uma área de atuação atrasa o processo, pois tem que envolver mais de uma pasta ministerial e identificar a atividade preponderante de acordo com as suas despesas (entrevistado \#02), sem contar que há exigência de outras atividades sociais para as OTS do setor educacional (entrevistado \#03). O entrevistado \#05 relatou que o sistema utilizado para a inserção dos dados das prestações de contas é engessado, gerando dificuldades no processo.

Processos internos dos ministérios com fragilidades operacionais têm atrapalhado os processos de certificação, segundo a entrevistada \#05. Ele relatou indeferimento de uma das prestações de contas, devido à alegação de não recebimento dos documentos do processo pelo Ministério da Educação, embora tivesse o protocolo dos Correios comprovando o envio da documentação. Além disso, há também as decisões equivocadas das OTS. O entrevistado \#08 afirmou que uma instituição, no final do exercício fiscal, inutilizou as informações e documentos contábeis depois de encerrar as atividades do ano, não permitindo a emissão do parecer da auditoria independente. Algumas OTS decidem seguir com o processo de certificação, mesmo sabendo que não atendem aos requerimentos da legislação (entrevistados \#02 e \#13). Ou seja, insistem no processo, provavelmente contando com os erros das equipes nos ministérios. 


\subsection{Os efeitos da Certificação Cebas}

Imunidade tributária. A imunidade tributária é apontada por todos os entrevistados como o motivador preponderante para a obtenção e renovação da certificação Cebas. Eles utilizam termos como: economicidade (\#06), imunidades tributárias (\#06,\#08,\#11,\#12), benefícios tributários (\#04,\#15,\#17)), renúncias fiscais (\#05), manutenção da isenção e do ato declaratório (\#09), isenção dos impostos (\#10, \#13, \#18), prerrogativa tributária (\#14) e garantia de benefícios da conta previdenciária patronal (\#16).

De acordo com o entrevistado \#16, a garantia de benefícios da cota previdenciária patronal é um peso muito grande para as instituições, que, normalmente, têm uma imensa folha de pagamento, para garantir os atendimentos sociais, os quais o Governo não conseguiria oferecer. O entrevistado \#05 destacou que, com a imunidade tributária, 'conseguimos garantir uma educação de qualidade para crianças carentes que não teriam acesso a esses serviços'.

O entrevistado \#18 relatou que a imunidade da cota previdenciária patronal, que é quase 25\% dos valores da folha de pagamento, além de outras isenções, como o PIS, é uma economia financeira. A certificação é muito boa para as instituições, para a aprovação de projetos, porque consegue fazer uma redução dos custos orçamentários. O entrevistado \#06 relatou que a imunidade tributária 'não é uma escolha do dirigente; se aquilo é o melhor para a entidade e se ele está administrando uma entidade de interesse público, ele tem a obrigação de "trilhar" o Cebas pela economicidade'.

Credibilidade das OTS. As organizações certificadas possuem um tratamento diferenciado junto ao poder público, por causa da conformidade com a ITG 2002 (CFC, 2012), que dá segurança ao administrador público, segundo o entrevistado \#06: 'Quem tem a certificação Cebas se destaca como uma entidade que tem melhores práticas de gestão'. A formação de parcerias junto ao poder público e as empresas privadas, de acordo com o entrevistado \#02, facilita a parceria com o SUS e projetos com o Conselho Municipal da Criança e do Adolescente (CMDAC).

Outro benefício diz respeito à melhora da imagem das OTS para o entrevistado \#08. Uma vez obtida a certificação Cebas, esta passa a ser um atestado de atendimento do aspecto social da entidade. Ou seja, a certificação atua como um fator social positivo. O entrevistado \#04 relata que traz mais credibilidade para a instituição, porque demonstra para a sociedade que a instituição cumpre os requisitos da ITG 2002 (CFC, 2012), ou seja, indica que, de fato, as OTS prestam serviços de assistência social, saúde e educação com a ratificação do poder público (entrevistado \#09).

Captação de recursos. Os impactos na captação de recursos mostram duas situações dicotômicas: benefícios e influências positivas do Cebas e pouca influência desta certificação. Atua como facilitador para captar recursos no Brasil e exterior (entrevistados \#01, \#06, \#09, \#13, \#16). As organizações internacionais veem com bons olhos as instituições certificadas com o Cebas. Essas boas práticas são um diferencial na captação de recursos, tanto no Brasil quanto internacionalmente. A certificação, ao exigir plano de atendimento, transparência, modelos de relatórios com critérios de comparação e demonstrações contábeis com base nas IFRS, influencia na transparência, segundo o entrevistado \#13, deixando os doadores internacionais mais confortáveis para doar recursos a essas OTS. Para o entrevistado \#06, 'a primeira grande captação é não gastar, por causa da imunidade'.

No ambiente internacional, o Cebas tem sido referência na de captação de recursos de fundos canadenses, da União Europeia e Reino Unido. Inúmeras entidades se habilitam, mas as entidades internacionais estão atentas a diferenciais e ao investidor social internacional, observando quem tem melhores condições de gestão e eficiência/eficácia (entrevistado \#06). Nesse contexto, a entrevistada \#01 relatou que o indeferimento da certificação da instituição na qual trabalha resultou em não recebimento de recursos oriundos do exterior e em aumento significativo dos custos em decorrência do pagamento dos tributos sobre a folha de pagamento.

Por outro lado, dependendo da instituição, o Cebas não traz vantagens competitivas, declarou o entrevistado \#11, ao fazer a seguinte exposição: 'Já tivemos instituições que deixaram a certificação propositalmente. Teve um caso em que uma instituição lutou muito pela isenção do ICMS, mas depois que conseguiu, não valeu a pena, devido a seus clientes não terem como aproveitar o crédito do imposto e, por isso, ela perdeu competitividade de mercado'. 
Para alguns entrevistados, a certificação não tem influência na captação de recursos, porque as OTS possuem outras fontes de receitas. Segundo o entrevistado \#15, a certificação Cebas não interfere na captação de recursos, porque a instituição é mantida por meio de anuidades escolares. Já para a entrevistada \#03, isso ocorre porque a entidade possui convênios com instituições públicas e privadas que não exigem a certificação Cebas. O entrevistado \#07, por sua vez, declarou que a instituição trabalha com atividades e projetos ambientais e tem um baixo custo com a folha de pagamento. Segundo o entrevistado \#12, as instituições estão fazendo um exame do custo-benefício para manter e renovar a certificação Cebas. Muitas delas têm a informação que os benefícios da imunidade já não são tão representativos (entrevistado \#12), ou optaram pela adequação da OTS como OSCIP (\#18). Outras preferem maior liberdade para trabalhar (\#11), estando livres das amarras dessa certificação, e reconhecem que outras legislações já garantem os benefícios dessa certificação (\#10).

Mudança cultural. Além dos antecedentes e dos efeitos da certificação Cebas, a sua manutenção é um desafio cultural. Segundo o entrevistado \#06, os gestores das OTS, muitas vezes, não dão a atenção necessária à relevância desta certificação, principalmente no que diz respeito aos seus efeitos. Esse entrevistado entende que a classe contábil é a grande fomentadora dessa mudança de cultura. Seu papel não se limita à prestação de serviços propriamente dita, ou seja, fazer somente o registro e a evidenciação adequada. Para o entrevistado \#02, o papel do contador tem se transformado ao longo do tempo, com foco em um papel mais consultivo na manutenção dessa certificação, ficando muito próximo das OTS para orientá-las, não ficando restrito somente à evidenciação adequada (\#06). Por exemplo, junto ao serviço social em uma análise de imposto de renda para a análise da renda per capita familiar (entrevistado \#02).

A Figura 2 apresenta o resumo desta discussão.

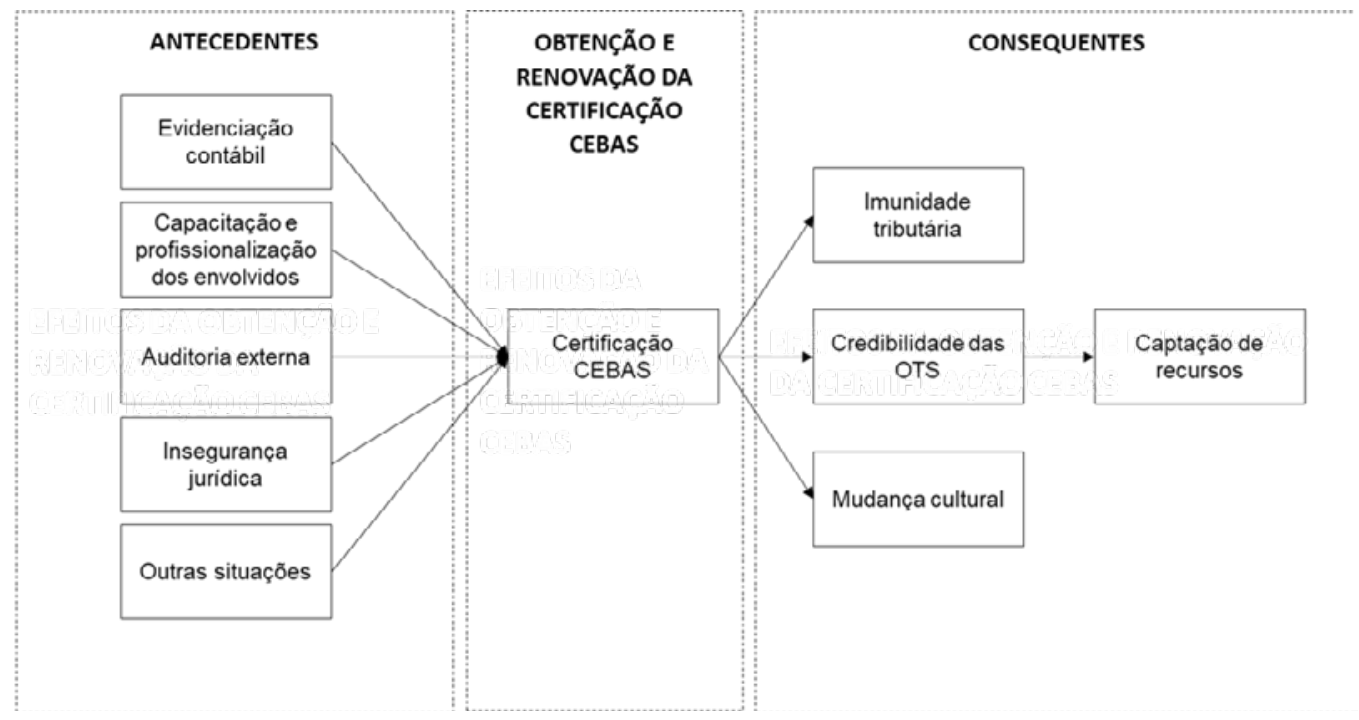

Figura 2. Antecedentes e consequentes da obtenção e renovação da certificação Cebas 


\section{Discussão dos Resultados}

A certificação Cebas legitima principalmente as imunidades tributárias das OTS nas perspectivas pragmática e moral. Na perspectiva da legitimidade pragmática, diz respeito principalmente à legitimidade de troca, pois os interesses do seu público imediato, das OTS, são atendidos no tocante aos benefícios tributários, que, por sua vez, facultam a legitimidade moral a essa certificação, pois há uma avaliação normativa positiva por esse público. Decorre principalmente da adoção de técnicas e procedimentos socialmente aceitos (legitimidade processual), conforme a tipologia de Suchman (1995).

Contudo, essa legitimidade se depara com algumas vulnerabilidades controláveis e não controláveis nos antecedentes dessa certificação, que podem comprometer tanto a legitimidade pragmática quanto a moral. As controláveis referem-se à evidenciação fiscal, contratação de auditoria externa e capacitação dos atores sociais, colocando em jogo a legitimidade pragmática. No Brasil, a contabilidade aplicada ao terceiro setor segue as normas da ITG 2002 (CFC, 2012), que estabelece os procedimentos e critérios técnicos para os registros e demonstrações contábeis das OTS. Aplica-se também as Normas Brasileiras de Contabilidade para as microempresas e empresas de pequeno porte ou as normas completas nos aspectos não abordados pela ITG 2002 (CFC, 2012). Assim, as regras contábeis aplicadas às OTS apresentam algumas diferenças em comparação àquelas aplicadas às demais organizações.

De fato, Silva, Da Silva, Penido Drumond, \& De Assis Valadares (2017) constataram que os erros encontrados nas demonstrações contábeis estão vinculados à utilização das regras contábeis gerais e não às específicas, conforme as exigências da ITG 2002 (CFC, 2012). Ramos e Klan (2019) mostraram um baixo índice de qualidade da informação contábil entre as OTS, independentemente da certificação Cebas. Por conseguinte, seus relatórios possuem baixa relevância para os stakeholders, em particular, para os entes fiscalizadores. Não são utilizados como instrumentos de prestação de contas para maior transparência na utilização e manutenção de suas imunidades tributárias e recursos financeiros.

Em outras palavras, a qualidade da informação fiscal é uma vulnerabilidade a ser mitigada pelos atores sociais desse processo, pois compromete a legitimidade pragmática da certificação Cebas, uma vez que algumas OTS têm tido dificuldades em atender à ITG 2002 (CFC, 2012), sendo este o principal motivo para o indeferimento, conforme os dados desta pesquisa. Assim, destaca-se a necessidade de investimentos na capacitação dos gestores das OTS e dos profissionais da contabilidade, não somente sobre todo o processo da certificação, mas também sobre as normas técnicas específicas do terceiro setor, como a ITG 2002 (CFC, 2012).

A legitimidade pragmática da certificação Cebas também pode estar comprometida, pela ausência da auditoria externa, principalmente no tocante aos custos desse serviço. Nesta pesquisa, as evidências também mostram a necessidade de reforçar o papel da auditoria externa, apesar das restrições orçamentárias das OTS, para assegurar maior confiabilidade ao processo de referida certificação e para atuar como fator de retroalimentação e aprendizagem de todos os atores sociais envolvidos neste processo. Harris, Tate, \& Zimmerman (2019) mostraram a relevância desse serviço para assegurar e aumentar a credibilidade das OTS nos Estados Unidos. Reheul, Van Caneghem, Van den Bogaerd, \& Verbruggen, 2017 constataram que auditores com experiência no setor de OTS têm menor probabilidade de divulgar erros nos relatórios de auditoria.

Em muitas instituições, a decisão de auditar as demonstrações contábeis é feita de maneira voluntária, por considerar as vantagens da realização da auditoria diante dos seus custos. Assim, os gestores podem utilizar a auditoria externa como um mecanismo de controle para diminuir os riscos. Contudo, a maioria das organizações de pequeno e médio porte não possuem disponibilidade financeira para a realização de auditorias independentes (Carrera \& Trombetta, 2018). Uma pequena parte das organizações sem fins lucrativos não contrata auditorias, devido à dificuldade financeira (Burks, 2015). Segundo Garven, Beck e Parsons (2018), as OTS com auditoria têm uma melhora na qualidade nas prestações de contas. O fato de não terem finalidades lucrativas não as distancias de possíveis conflitos de agência. Também mostraram que auditores com contratos superiores a três anos podem ter sua independência comprometida, o que também pode afetar a qualidade das demonstrações. 
As vulnerabilidades não controláveis envolvendo a insegurança jurídica e outras situações, principalmente no que se refere aos procedimentos e processos internos dos Ministérios da Saúde, Educação e Assistência Social também contribuem para enfraquecer a legitimidade pragmática e moral da certificação Cebas. A insegurança jurídica acerca das legislações da certificação está posta! Assim, cabe às OTS a implementação de procedimentos de conformidade e organização da gestão nos processos de certificação nas OTS, inclusive a revisão de todos os procedimentos e cruzamento das informações entre os setores. Fagundes, Silva e Silva (2014) já apontaram que insegurança jurídica, além das ineficiências, arbitrariedades e corrupção deixam as relações entre OTS e União mais distantes, em função das complexidades contextuais das certificações, incluindo a Cebas.

Em relação aos efeitos dessa certificação, a imunidade tributária ainda é um dos principais motivadores dos pedidos de concessão e renovação do Cebas, portanto, o efeito mais esperado, aquele que mais contribui para a legitimidade moral. Contudo, as evidências também mostram que algumas organizações não veem o valor dessa certificação para outros benefícios, como aumento da credibilidade e, por conseguinte, elevação da captação de recursos. Nos Estados Unidos e na Europa (Yörük, 2016; Gordon, Knock, \& Neely, 2009; Ortmann \& Svítková, 2007), as certificações melhoram o processo de captação de recursos. As OTS que têm o apoio de assessorias especializadas utilizam as certificações como critério de credibilidade, melhorando a capitação de recursos, não ficando restritas às imunidades (Adena et al., 2019).

No Brasil, as OTS podem explorar mais a certificação Cebas não somente para benefícios tributários, mas também para a captação de recursos nacionais e internacionais. Essa prática é pouco utilizada no Brasil, principalmente nas OTS de pequeno porte e naquelas onde já se tem uma garantia de recursos, como as instituições de educação regular, que recebem mensalidades escolares. Esse fato demonstra a necessidade de mudança cultural dos gestores das OTS e dos contadores, para que possam utilizar a certificação para aumentar a credibilidade das organizações e a captação de recursos. Carroll \& Stater (2009) mostraram que a diversidade de receitas em instituições sem fins lucrativos proporciona maior estabilidade financeira.

A utilização da certificação acarreta maiores controles administrativos nas OTS, garantindo-lhes maior credibilidade e transparência junto à sociedade. Mostra também a capacidade dos contadores na utilização das demonstrações contábeis nas tomadas de decisão. O gerenciamento de custos já é utilizado para a tomada de decisão na avaliação dos benefícios da certificação comparados aos custos da sua manutenção. Assim, insere-se a contabilidade no processo de tomada de decisões das OTS, como já indicavam os estudos Lima e Pereira (2004), de que a contabilidade pode apoiar essa tomada de decisão e a gestão das organizações.

Ao explorar a certificação Cebas para a captação de recursos nacionais e internacionais, as OTS contribuem para fortalecer a legitimidade moral e pragmática dessa certificação, pois um dos motivos para se buscar a legitimidade é a continuidade dos seus negócios e a credibilidade das OTS, de que são organizações coerentes e confiáveis, segundo a proposta de Suchman (1995). Nesse caso, a legitimidade moral é mais reforçada do que a pragmática, pois ampliam-se os benefícios para as OTS.

Finalmente, as evidências revelam que, aparentemente, essas OTS estão vivenciando um processo de mudança isomórfica institucional. Isomorfismo refere-se a um processo em resposta às forças restritivas da ambiência externa destas OTS, forçando-as a se tornarem similares aos seus pares/concorrentes (DiMaggio \& Powell, 1983). Nesse caso, por meio do mecanismo do mimetismo. Ou seja, as OTS estão se ajustando a uma nova situação, se adaptando diante da incerteza simbólica, ao seguirem outras entidades tidas como modelo, por serem bem-sucedidas na obtenção e manutenção da certificação Cebas. 


\section{Considerações Finais}

Este estudo contribui com um modelo conceitual holístico baseado nos eventos antecedentes da política pública associada ao Cebas e nos seus efeitos, ainda não discutido na literatura nacional, podendo ser testado em futuras pesquisas quantitativas. Também contribui ao aprofundar o entendimento das vulnerabilidades controláveis e não controláveis ao longo desse processo, bem como ao mostrar a pouca relevância e utilidade que essa certificação pode ter para a captação de recursos, uma vez que os gestores das OTS só almejam as imunidades tributárias.

O estudo alerta para a perda de oportunidades de aumentar a quantidade de doadores, nos níveis individual e organizacional, expondo a miopia dessa certificação. $\mathrm{O}$ estudo também destaca a necessidade de mitigar tais vulnerabilidade para fortalecer a legitimidade pragmática e moral dessa certificação e, por conseguinte, fortalecendo a gestão das OTS, pois além de utilizarem as imunidades tributárias em seus planejamentos tributários, podem ter uma gestão financeira pautada no aumento dos recursos por parte dos doadores nacionais e internacionais. Ou seja, trata-se de aplicar a contabilidade para a sustentabilidade à 'estratégia da empresa, avaliando riscos e oportunidades e fornecendo habilidades de medição, contabilidade e gerenciamento de desempenho para garantir que a sustentabilidade esteja incorporada às operações do dia a dia da empresa', segundo o Instituto Americano de Contadores Públicos Certificados (AICPA, 2021).

Assim, como contribuição teórica, este estudo pode ampliar a literatura sobre certificações, ao discutir os impactos das demonstrações contábeis na obtenção da certificação Cebas. A pesquisa pode contribuir ainda para os praticantes, tanto do setor público quanto do terceiro setor, ao identificar as principais diligências nos relatórios técnicos analisados pelo setor de julgamento dos processos de concessão e renovação da certificação. Ao fazer isso, pode contribuir para a criação de mecanismos de conformidades que poderão ajudar as OTS na prevenção e correção das prestações de contas futuras. Outra contribuição prática é a deflagração de ações de capacitação dos profissionais da contabilidade pelo Conselho Federal de Contabilidade.

\section{Referências}

Adena, M., Alizade, J., Bohner, F., Harke, J., \& Mesters, F. (2019). Quality certification for nonprofits, charitable giving, and donor's trust: Experimental evidence. Journal of Economic Behavior and Organization, 159, pp. 75-100. Doi: https://doi.org/10.1016/j.jebo.2019.01.007

AICPA. American Institute of Certified Public Accountants. (2021). Sustainability Accounting. Acesso em janeiro 2021: Recuperado de: https://www.aicpa.org/interestareas/businessindustryandgovernment/ resources/sustainability/sustainability-accounting.html

Atasoy, A. T. (2020). Behavioral responses of green builders to discontinuous certification schemes. Resource and Energy Economics, 60, 101141. Doi: https://doi.org/10.1016/j.reseneeco.2019.101141

Auld, G., Gulbrandsen, L. H., \& McDermott, C. L. (2008). Certification schemes and the impacts on forests and forestry. Annual Review of Environment and Resources, 33, pp. 187-211. Doi: https:// doi.org/10.1146/annurev.environ.33.013007.103754

Barragato, C. A. (2019). The impact of accounting regulation on non-profit revenue recognition. Journal of Applied Accounting Research, 20(2), pp. 190-206. Doi: https://doi.org/10.1108/JAAR-03-2017-0041

Beuren, I. M., \& Tamanini, D. (2009). Controle das ações sociais em instituições de ensino superior para renovação do certificado de entidade beneficente e assistência social. Enfoque: Reflexão Contábil, 28(1), pp. 09-26. Doi: https://doi.org/10.4025/enfoque.v28i1.4719

Boateng, A., Akamavi, R. K., \& Ndoro, G. (2016). Measuring performance of non-profit organisations: Evidence from large charities. Business Ethics, 25(1), pp. 59-74. Doi: https://doi.org/10.1111/ beer. 12108 
Bomtempo, E., \& Valadão, M. A. P. (2017). Análise Juseconômica da Imunidade Tributária Musical: O Caso do E- Music no Brasil. Economic Analysis of Law Review, 7(2), pp: 679-713. Recuperado de: https://bdtd.ucb.br/index.php/EALR/article/view/7179

Brown, A. L., Meer, J., \& Williams, J. F. (2017). Social distance and quality ratings in charity choice. Journal of Behavioral and Experimental Economics, 66, pp. 9-15. Doi: https://doi.org/10.1016/j. socec.2016.04.006

Burks, J. J. (2015). Accounting errors in nonprofit organizations. Accounting Horizons, 29(2), pp. 341-361. Doi: https://doi.org/10.2308/acch-51017

Carrera, N., \& Trombetta, M. (2018, January 1). A pequena vira grande! O papel das "pequenas" auditorias no estudo do mercado de auditoria. Revista Contabilidade e Financas, 29, pp. 9-15. Doi: https://doi. org/10.1590/1808-057x201890230

Carroll, D. A., \& Stater, K. J. (2009). Revenue diversification in nonprofit organizations: Does it lead to financial stability? Journal of Public Administration Research and Theory, 19(4), pp. 947-966. Doi: https://doi.org/10.1093/jopart/mun025

Cavero-Rubio, J. A., \& Amorós-Martínez, A. (2020). Environmental certification and Spanish hotels' performance in the 2008 financial crisis. Journal of Sustainable Tourism, 28(5), pp. 771-796. Doi: https://doi.org/10.1080/09669582.2019.1705316

CFC. Conselho Federal de Contabilidade. (2012). Resolução n. 1.409, de 21 de setembro de 2012. Aprova a ITG 2002 - Entidade sem Finalidade de Lucros. Recuperado de https://www2.cfc.org.br/sisweb/sre/ detalhes_sre.aspx?Codigo=2015/ITG2002(R1).\&Codigo=2015/ITG2002(R1). Acesso em Junho 2019.

Costa, E., \& Pesci, C. (2016). Social impact measurement: why do stakeholders matter? Sustainability Accounting, Management and Policy Journal, 7(1), pp. 99-124. Doi: https://doi.org/10.1108/ SAMPJ-12-2014-0092

Degnet, M. B., van der Werf, E., Ingram, V., \& Wesseler, J. (2018). Forest plantations' investments in social services and local infrastructure: an analysis of private, FSC certified and state-owned, non-certified plantations in rural Tanzania. Land Use Policy, 79(July), pp. 68-83. Doi: https://doi.org/10.1016/j. landusepol.2018.07.041

DiMaggio, P., \& Powell, W. (2000). The iron cage revisited institutional isomorphism and collective rationality in organizational fields. In J. A. C. Baum \& F. Dobbin (Eds.), Economics Meets Sociology in Strategic Management pp. 143-166. Doi: https://doi.org/10.1016/S0742-3322(00)17011-1

Fagundes, L. R., Silva, V. A. A., \& Silva, C. E. G. (2014). Certificações públicas concedidas às organizações da sociedade civil no Brasil. Entre dimensões normativas e complexidades contextuais. Cadernos Gestão Pública e Cidadania, 19(64), pp. 41-57. Doi: https://doi.org/10.12660/cgpc.v19n64.8930

Fonif. Fórum Nacional das Instituições Filantrópicas. (2018). Pesquisa: A contrapartida do setor filantrópico para o Brasil. Recuperado de: http://www.asav.org.br/wp-content/uploads/2019/04/ Pesquisa-Setor-filantr\%C3\%B3pico-2018-FONIF.pdf

Garven, S. A., Beck, A. W., \& Parsons, L. M. (2018). Are audit-related factors associated with financial reporting quality in nonprofit organizations? Auditing, 37(1), pp. 49-68. Doi: https://doi. org/10.2308/ajpt-51819

Gidron, B. (2010). Promoting civil society in Third Sector organizations through participatory management patterns. European Management Journal, 28(6), pp. 403-412. Doi: https://doi.org/10.1016/j. emj.2010.06.005

Gordon, T. P., Knock, C. L., \& Neely, D. G. (2009). The role of rating agencies in the market for charitable contributions: An empirical test. Journal of Accounting and Public Policy, 28(6), pp. 469-484. Doi: https://doi.org/10.1016/j.jaccpubpol.2009.08.001 
Grieco, C., Michelini, L., \& Iasevoli, G. (2015). Measuring Value Creation in Social Enterprises: A Cluster Analysis of Social Impact Assessment Models. Nonprofit and Voluntary Sector Quarterly, 44(6), pp. 1173-1193. Doi: https://doi.org/10.1177/0899764014555986

Grizzle, C., \& Sloan, M. F. (2016). Assessing changing accountability structures created by emerging equity markets in the nonprofit sector Markets in the Nonprofit Sector. Public Administration Quarterly, 40(2), pp. 387-408. Recuperado em 28 de maio de 2021 de: https://www.jstor.org/stable/24772936

Harris, E. E., Tate, S. L., \& Zimmerman, A. B. (2019). Does Hiring a Local Industry Specialist Auditor Matter to Nonprofit Organizations? Nonprofit and Voluntary Sector Quarterly, 48(3), pp. 633-664. Doi: https://doi.org/10.1177/0899764018784752

Khieng, S. (2014). Funding Mobilization Strategies of Nongovernmental Organizations in Cambodia. Voluntas, 25(6), pp. 1441-1464. Doi: https://doi.org/10.1007/s11266-013-9400-7

Krasteva, S., \& Yildirim, H. (2016). Information, competition, and the quality of charities. Journal of Public Economics, 144, pp. 64-77. Doi: https://doi.org/10.1016/j.jpubeco.2016.10.008

Lima, E. M., \& Pereira, C. A. (2004). Apuração e evidenciação dos resultados das instituições de ensino superior com certificado de entidade beneficente de assistência social. Revista Contabilidade \& Finanças, 15(36), pp. 35-49. Doi: https://doi.org/10.1590/s1519-70772004000300007

Merriam, S. (1998). Qualitative Research and Case Study Applications in Education. Revised and Expanded from" Case Study Research in Education.". Recuperado de http://www.eric.ed.gov/ERICWebPortal/ recordDetail?accno=ED415771

Mohan, S. (2020). Risk aversion and certification: Evidence from the Nepali tea fields. World Development, pp. 129. Doi: https://doi.org/10.1016/j.worlddev.2020.104903

Niedziałkowski, K., \& Shkaruba, A. (2018). Governance and legitimacy of the Forest Stewardship Council certification in the national contexts-A comparative study of Belarus and Poland. Forest Policy and Economics, 97, pp. 180-188. Doi: https://doi.org/10.1016/j.forpol.2018.10.005

ONU. Organização das Nações Unidas. (2015). Sobre o nosso trabalho para alcançar os Objetivos de Desenvolvimento Sustentável no Brasil. Recuperado em janeiro 2021 de: https://brasil.un.org/pt-br/sdgs

Ortmann, A., \& Svítková, K. (2007). Certification as a Viable Quality Assurance Mechanism in Transition Economies: Evidence, Theory, and Open Questions. Prague Economic Papers, 16(2), pp. 99-114. Doi: https://doi.org/10.18267/j.pep.300

Ramos, F. M., \& Klann, R. C. (2019). Relationship between quality in accounting information and organizational characteristics of the third sector entities. Organizações \& Sociedade, 26(88), pp. 9-27. Doi: https://doi.org/10.1590/1984-9260881

Reheul, A. M., Van Caneghem, T., Van den Bogaerd, M., \& Verbruggen, S. (2017). Auditor gender, experience and reporting in nonprofit organizations. Managerial Auditing Journal, 32(6), pp. 550577. Doi: https://doi.org/10.1108/MAJ-01-2016-1296

Santos, C. M. V. dos, Ohayon, P., \& Pimenta, M. M. (2017). Disclosure via website e as características das empresas do terceiro setor: um estudo empírico das entidades cariocaS. Advances in Scientific and Applied Accounting, 10(1), pp. 073-090. Doi: https://doi.org/10.14392/asaa.2017100105

Schepers, D. H. (2010). Challenges to legitimacy at the Forest Stewardship Council. Journal of Business Ethics, 92(2), pp. 279-290. Doi: 10.1007/s10551-009-0154-5charity

Silva, C. M., Da Silva, J. R., Penido Drumond, F. M., \& De Assis Valadares, J. P. (2017). Entidades Do Terceiro Setor: estudo de casos múltiplos da adoção da itg 2002 em prestações de contas de fundações mineiras de direito privado. SINERGIA - Revista do Instituto de Ciências Econômicas, Administrativas e Contábeis, 21(1), pp. 9-20. Doi: https://doi.org/10.17648/sinergia-2236-7608-v21n1-5324 
Svítková, K. (2013). Certification and its impact on quality of charities. Prague Economic Papers, 22(4), pp. 542-557. Doi: https://doi.org/10.18267/j.pep.467

Weisbrod, B. A., \& Dominguez, N. D. (1986). Demand for collective goods in private nonprofit markets: Can fundraising expenditures help overcome free-rider behavior? Journal of Public Economics, 30(1), pp. 83-96. Doi: https://doi.org/10.1016/0047-2727(86)90078-2

Wen, H., \& Lee, C. C. (2020). Impact of environmental labeling certification on firm performance: Empirical evidence from China. Journal of Cleaner Production, 255, 120201.Doi: https://doi. org/10.1016/j.jclepro.2020.120201

Williams, A. P., \& Taylor, J. A. (2013). Resolving Accountability Ambiguity in Nonprofit Organizations. Voluntas, 24(3), pp. 559-580. Doi: https://doi.org/10.1007/s11266-012-9266-0

Yörük, B. K. (2016). Charity Ratings. Journal of Economics and Management Strategy, 25(1), pp. 195-219. Doi: https://doi.org/10.1111/jems.12139 